\title{
A survival analysis of patients with an acute exacerbation of chronic obstructive pulmonary disease discharged from the respiratory intensive care unit
}

\author{
Jie Cheng", Min Lu", Huijuan Sun, Yanjun Mao \\ Department of Respiratory Intensive Care Unit, Shanghai Pulmonary Hospital, Tongji University, Shanghai, China \\ Contributions: (I) Conception and design: J Cheng, M Lu; (II) Administrative support: Y Mao ; (III) Provision of study materials or patients: H Sun; (IV) \\ Collection and assembly of data: J Cheng, M Lu, H Sun; (V) Data analysis and interpretation: J Cheng, M Lu; (VI) Manuscript writing: All authors; \\ (VII) Final approval of manuscript: All authors. \\ \#These authors contributed equally to this work. \\ Correspondence to: Yanjun Mao. Shanghai Pulmonary Hospital, Tongji University, Shanghai 200433, China. Email: maoyanjun_fk@tongji.edu.cn.
}

\begin{abstract}
Background: To analyse the survival of patients with acute exacerbation of chronic obstructive pulmonary disease (AECOPD) after discharge from respiratory intensive care unit (RICU) and the adverse factors affecting patient's survival, so as to improve the follow-up work in the future.

Methods: A retrospective observational study was conducted in the RICU. Patient demographic and clinical data were collected before discharge.

Results: All patients were followed for 2 years after discharge. Living status was collected. The LogRank test was used to compare the survival distributions at 24 months, and the Kaplan-Meier curve was plotted. Multivariate Cox regression analysis was performed. A total of 159 patients were admitted to the RICU; 19 patients died in the hospital. The post-hospitalization mortality was $18.24 \%$ (29/159), 27.04\% (43/159), and 37.11\% (59/159), respectively, at 6, 12 and 24 months. Data from a total of 140 discharged patients were collected and analysed. Old age, no education, low BMI, bedridden status, comorbidity with bronchiectasis, and comorbidity with cancer were risk factors affecting the survival rate of patients with an acute exacerbation of chronic obstructive pulmonary disease (COPD) as analysed by the Log-Rank test. Multivariate Cox regression analysis showed that old age, no education, and low BMI were independent factors affecting patient survival.

Conclusions: In China, there are many older patients who have no education, and it may be very important for patients with an acute exacerbation of COPD to have additional specialized health education after discharge.
\end{abstract}

Keywords: Acute exacerbation of chronic obstructive pulmonary disease (AECOPD); respiratory intensive care unit (RICU); follow-up; Chinese people

Submitted Dec 23, 2019. Accepted for publication Feb 27, 2020.

doi: 10.21037/apm.2020.04.30

View this article at: http://dx.doi.org/10.21037/apm.2020.04.30

\section{Introduction}

Chronic obstructive pulmonary disease (COPD) is a common and frequently occurring disease that seriously affects human health, has a high mortality rate, and imposes a heavy economic burden on patients, their families and society. COPD is currently the fourth leading cause of death in the world (1) and seriously affects the quality of life of patients. In China, the prevalence of COPD is $8.2 \%$ (men, 12.4\%; women, $5.1 \%$ ) in people 40 years of age or older (2). COPD exacerbation will accelerate disease progression, which results in hospital admission and death. Exacerbation of COPD is a major factor affecting COPD- 
related mortality (3). The in-hospital mortality is $4.9 \%$ (4) in Europe and 3.9-4.8\% (5) in the USA according to the statistics of national databases. The mortality will rise if the number of patients with respiratory failure, heart failure, and other serious complications increases. The hospital mortality in the ICU is $16.4 \%$ (6) to $23.8 \%$ (7).

As China ages, the number of patients with chronic respiratory diseases increases. The facilities and staffing of general wards have been difficult to meet the needs of patients with severe respiratory. To address the treatment of the severe respiratory patients, Shanghai Pulmonary Hospital founded a respiratory intensive care unit (RICU) with 6-bed in 2015. It is equipped with all ultra modern facilities including invasive and non-invasive ventilator, transfer ventilator, ECG monitor, central monitor, heart defibrillator, bronchoscope, aspirator, infusion pump, syringe pump and many more. Four pulmonologist (2 MDs and 2 masters) work for RICU. To ensure nurse-patient ratio was 1:2 and 18 nurses are deployed in our RICU (general respiratory ward nurse-patient ratio was 1:8). Acute exacerbation of COPD (AECOPD) is one of the most severe respiratory diseases among the patients admitted to the RICU. Follow-up after discharge from these AECOPD patients presented a high mortality rate. This study was to analyse the survival of the patients with AECOPD after discharge from RICU and the adverse factors affecting patients' survival, so as to improve the follow-up work in the future.

\section{Methods}

\section{Study design}

A retrospective observational study was conducted in the 6-bed RICU in Shanghai Pulmonary Hospital, which is a 1,000-bed tertiary medical centre. AECOPD patients were collected between April 10, 2015, and July 5, 2017. This study was approved by the Human Ethics Committee of Shanghai Pulmonary Hospital (No. k18-125), and all subjects or family members were willing to accept this survey. As the study was retrospective, a waiver of informed consent was obtained from the human ethics committee. The data of patients were anonymised. The study was conducted in accordance with the Declaration of Helsinki (as revised in 2013).

COPD exacerbations are defined as an acute worsening of respiratory symptoms that results in additional therapy (8) and are characterized by a change in the patient's baseline dyspnoea, cough and/or sputum beyond dayto-day variability that is sufficient to warrant a change in management (9). The classification of severity can be ranked by the clinical relevance of the episode and its outcome: level I: treat at home; level II: requires hospitalization; and level III: leads to respiratory failure. Level II AECOPD patients with serious pulmonary infection and level III AECOPD patients with respiratory failure who were transferred to the RICU ward because of their critical symptoms were enrolled in this study. Patients were excluded from the study if death occurred during the hospital stay. The Life-threatening AECOPD patients admitted to ICU, which the indications for RICU admission based on the consensus of Chinese experts (10): (I) severe dyspnea and poor response to initial treatment; (II) disturbance of consciousness (such as lethargy, coma, etc.); (III) hypoxemia $\left(\mathrm{PaO}_{2}<40 \mathrm{mmHg}\right)$ continues or progresses progressively, and/or severe respiratory acidosis ( $\mathrm{pH}$ value $<7.25$ ) no remission or even deterioration, after oxygen therapy and non-invasive mechanical ventilation (3). Invasive mechanical ventilation was required; (IV) hemodynamic instability requires the use of vasopressor.

\section{Patients}

A case report form (CRF) was constructed to collect patient demographic and clinical data. Categorical variables including age, gender, education, height, weight, income (monthly per capita income), health insurance, marital status, and living status, were included in the demographic data. BMI was calculated from height and weight. Categorical variables including bedridden status, comorbidity with bronchiectasis, comorbidity with cancer, mechanical ventilation, smoking history, first admission for AECOPD, duration of COPD, transfer to a rehabilitation hospital after discharge, hypertension, chronic pulmonary heart disease, cardiovascular disease, diabetes, respiratory failure, $\mathrm{pH}$ value, and hypoproteinaemia, were included in the clinical data.

All patients were followed for 2 years after discharge. A Wechat (China's version of WhatsApp) group and a telephone call were conducted at 6,12, and 24 months for patient follow-up. The following survival data were collected: the death of the patients as an endpoint event and the withdrawal or family refusal to visit as the date of censoring.

\section{Statistical analyses}

The data in the CRF were entered into EpiData (version 
4.1) with double entry. After completing the entry, the data were exported to an SPSS file. The statistical analysis was performed using IBM SPSS Statistics 20.0 software. Descriptive statistics are presented as the mean \pm SD or medium (interquartile ranges) for continuous variables and frequencies for categorical variables. The Log-Rank test was used to compare the survival distributions at 24 months, and the Kaplan-Meier curve was plotted. Variables, if $\mathrm{P}<0.10$ in Log-Rank test were included in the Cox regression (Enter) for multivariate analysis. $\mathrm{P}<0.05$ in all statistical analyses was statistically significant.

\section{Results}

\section{Sample characteristics}

There were 524 patients with severe respiratory disease who were discharged or died in the hospital from April 10, 2015, to July 5, 2017. One hundred and sixty-nine of these admissions were AECOPD patients; among of them, 8 patients were admitted twice, and one patient was admitted three times. Therefore, data from 159 AECOPD patients were collected.

A total of 19 patients (all 19 were males) died in the hospital; the hospital mortality was $11.95 \%$. These 19 patients were $55-84$ years old $(76.1 \pm 8.4$ years old), and 12 of them were bedridden. The median hospital stay was 11 days (7-20 days). Nine patients received invasive mechanical ventilation treatment, 4 patients received noninvasive mechanical ventilation treatment. Thirteen patients had type 2 respiratory failure, and 1 patient had type 1 respiratory failure.

Finally, 140 patients discharged from RICU were enrolled in this study; these patients were $34-89$ years old (71.91 \pm 9.14 years old). The median hospital stay was 8 days (6-11 days), the median COPD history was 10.00 years (5.25-20.00 years), and the median hospital fee was 21,464 CNY (17,181-28,073 CNY; $100 \mathrm{CNY} \approx 14.49 \mathrm{USD})$.

\section{Demographic results}

The demographic characteristics for the 140 patients are shown in Table 1. Twenty-four months after the patients were discharged from the hospital, there were no significant differences in gender, income, health insurance, marital status, or living status in the survival distributions analysed
Table 1 Demographic characteristics of patients discharged from the RICU with stable COPD ( $\mathrm{n}=140)$

\begin{tabular}{|c|c|c|c|c|}
\hline Variables & $\begin{array}{c}\text { Discharged } \\
\text { with stable } \\
\text { COPD }\end{array}$ & Death & $\chi^{2}$ value & $P$ value \\
\hline Age in years & & & 7.048 & 0.008 \\
\hline$<80$ years old & 113 & 27 & & \\
\hline$\geq 80$ years old & 27 & 13 & & \\
\hline Gender & & & 0.052 & 0.820 \\
\hline Male & 121 & 35 & & \\
\hline Female & 19 & 5 & & \\
\hline Education & & & 10.564 & 0.005 \\
\hline No education & 81 & 31 & & \\
\hline Primary school & 33 & 8 & & \\
\hline $\begin{array}{l}\text { Junior high school or } \\
\text { higher }\end{array}$ & 26 & 1 & & \\
\hline Low BMI $(<18.5$ kg/m²) & & & 7.890 & 0.005 \\
\hline Yes & 57 & 24 & & \\
\hline No & 83 & 16 & & \\
\hline Income & & & 4.072 & 0.254 \\
\hline$<1,000 \mathrm{CNY}$ & 36 & 11 & & \\
\hline 1,000-3,999 CNY & 52 & 19 & & \\
\hline 4,000-4,999 CNY & 24 & 5 & & \\
\hline$\geq 5,000 \mathrm{CNY}$ & 28 & 5 & & \\
\hline Health insurance & & & 0.022 & 0.882 \\
\hline Out-of-pocket & 53 & 16 & & \\
\hline Social health insurance & 87 & 24 & & \\
\hline $\begin{array}{l}\text { Commercial health } \\
\text { insurance }\end{array}$ & 0 & 0 & & \\
\hline $\begin{array}{l}\text { Social \& commercial } \\
\text { health insurance }\end{array}$ & 0 & 0 & & \\
\hline Marital status & & & 0.023 & 0.880 \\
\hline Single & 8 & 2 & & \\
\hline Married & 132 & 38 & & \\
\hline Living alone & & & 0.166 & 0.684 \\
\hline Yes & 5 & 1 & & \\
\hline No & 135 & 39 & & \\
\hline
\end{tabular}

RICU, respiratory intensive care unit; COPD, chronic obstructive pulmonary disease. 
by Log-Rank tests (all $\mathrm{P}>0.05$ ). There were significant differences in education, BMI, and age (years) in the survival distributions analysed by Log-Rank tests. The cumulative survival rates by education, BMI, and age (years) are shown in Figure 1A,B,C.

\section{Clinical characteristics}

Follow-ups were performed at 6,12 and 24 months after the patient was discharged from the hospital, with mortality rates of $7.14 \%$ (10 cases), $17.14 \%$ ( 24 cases), and $28.57 \%$ (40 cases), respectively, at 6,12 and 24 months. The posthospitalization mortality of the patients was $18.24 \%$ (29/159), $27.04 \%(43 / 159)$, and $37.11 \%(59 / 159)$ at 6,12 and 24 months, respectively.

Twenty-four months after the 140 patients were discharged from the hospital, there were no significant differences by mechanical ventilation, smoking history, first admission for AECOPD, duration of COPD, transfer to a rehabilitation hospital after discharge, hypertension, chronic pulmonary heart disease, cardiovascular disease, diabetes, respiratory failure, $\mathrm{pH}$ value, comorbidity with bronchiectasis, or hypoproteinaemia in the survival distributions analysed by Log-Rank tests, all $\mathrm{P}>0.05$ (Table 2). There were significant differences in the survival distributions among patients who were bedridden $(\mathrm{P}=0.023)$ and comorbidity with cancer $(\mathrm{P}=0.039)$ as analysed by LogRank tests. The cumulative survival rates are shown in Figure 1D,E.

\section{Cox analysis results}

Age in years, education, low BMI, bedridden status, comorbidity with bronchiectasis, and comorbidity with cancer variables were selected to perform a Cox regression analysis (Enter) because of their biological relationship with the disease and their $\mathrm{P}$ value less than 0.10 in the Log-Rank test. The Cox regression analysis showed that older age and low BMI were independent factors affecting patient survival (see Table 3). Compared with patients who had a junior high school education or higher, patients with no education had a more than 8 -fold risk of death after discharge.

\section{Discussion}

There is a high mortality in AECOPD; only approximately one-half of COPD patients live more than 5 years after being hospitalized for an exacerbation (11-13). The AECOPD mortality is $12-33 \%$ after 1 year $(13-15)$ and $26-40 \%$ after 2 years $(12,13,16)$. Because the RICU was recently established, this study was only able to conduct a 2-year follow-up. The post-hospitalization mortality rate of the patients was $27.04 \%$ (43/159) after a year and $37.11 \%$ (59/159) after 2 years in this survey. In GOLD 2017, it was suggested that long-acting bronchodilators are initiated as soon as possible before hospital discharge (8). All 140 patients in this study were prescribed bronchodilators and corticosteroids, and antibiotics were prescribed as needed. It may be excluded that the 19 most severe AECOPD patients died in hospitals. Although patients in this study who were admitted in RICU, the mortality rate after discharge was not higher than previous reports. Patients with AECOPD have a similar prognosis if the severe infection and respiratory failure had been corrected.

There were many risk factors for mortality associated with AECOPD that are listed in Halpin's review (17). In this study, we found that age $>80$ years, level of education, low BMI, bedridden status, and comorbidity with cancer were risk factors for mortality in the Kaplan-Meier analyses. There were no significant differences in smoking, comorbidities, or other risk factors that were listed in the review. The reason for these differences may be that the AECOPD patients is this study were discharged from the RICU, and the patient's health status was different from that reported in other studies. In blood gas analyses, the blood $\mathrm{pH}$ value and hypoproteinaemia at admission did not affect the patient's survival after discharge. This study did not compare $\mathrm{PaO}_{2}, \mathrm{PaCO}_{2}$, and $\mathrm{SPO}_{2}$, which are used to observe respiratory failure in patients and are included in the diagnosis of acute respiratory failure. Acute respiratory failure was not a risk affecting death after discharge as long as it was corrected during hospitalization. As long as the patient's respiratory failure is corrected during hospitalization, the prognosis is generally good.

Cardiovascular disease does not predict the exacerbation rate or mortality in COPD (18). In this study, neither chronic pulmonary heart disease secondary to COPD nor other cardiovascular diseases affected the survival rate of patients. Non-invasive ventilation is recommended as a first-line treatment for AECOPD patients with acute respiratory failure in the new guidelines $(8,19)$. In this study, there were 96 acute respiratory failure patients, but only 5 patients were treated with non-invasive ventilation. It was possible that the guidelines in those years did not strongly recommend the use of non-invasive ventilation. Soon 

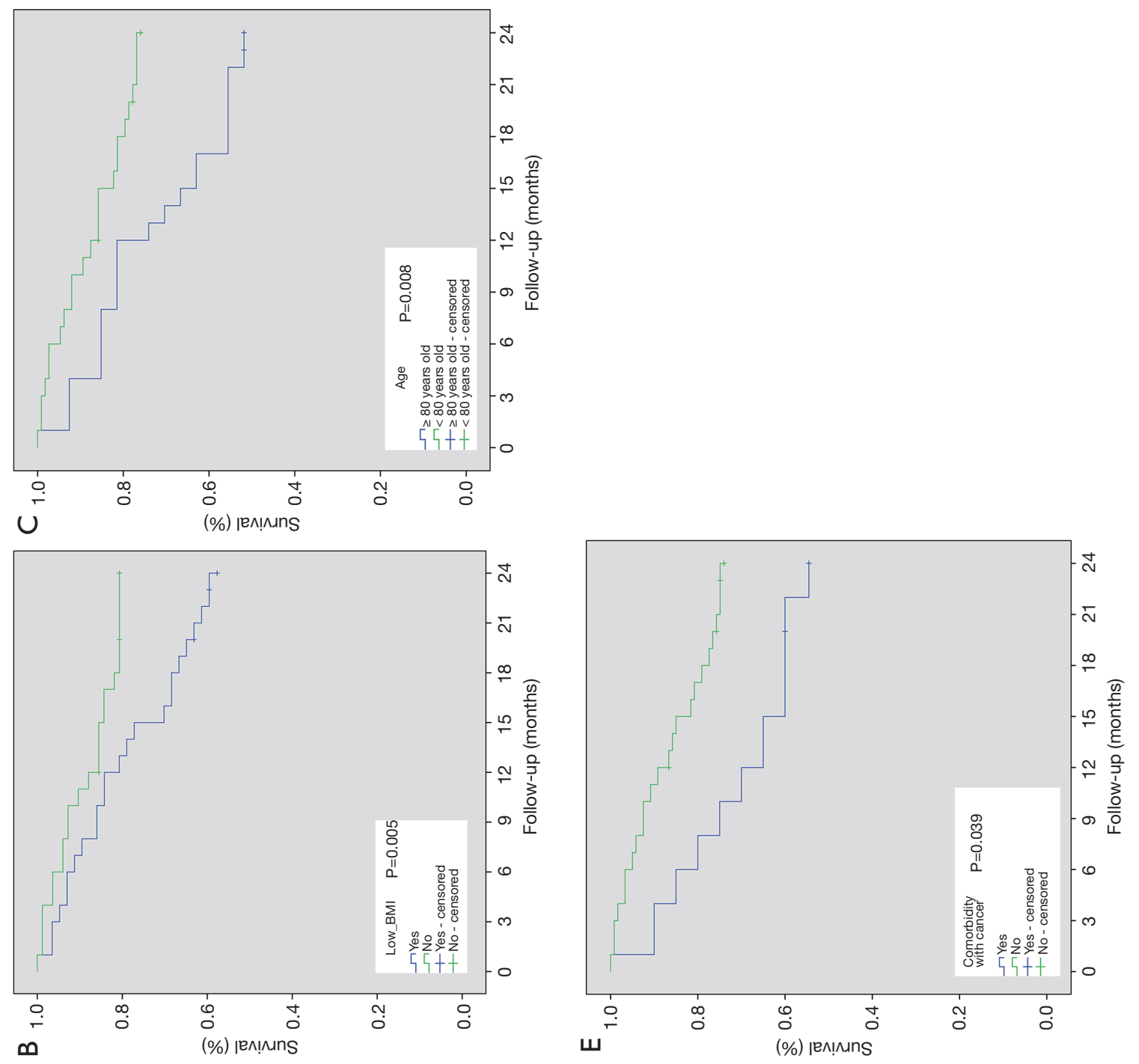

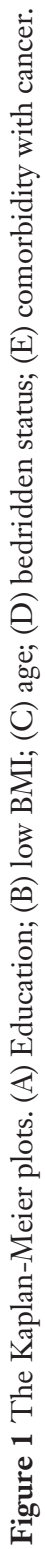


Table 2 Clinical characteristics of the patients discharged from the RICU with stable COPD ( $\mathrm{n}=140)$

\begin{tabular}{|c|c|c|c|c|}
\hline Variables & $\begin{array}{c}\text { Discharged } \\
\text { with stable } \\
\text { COPD }\end{array}$ & Death & $\chi^{2}$ value & $P$ value \\
\hline Bedridden & & & 5.139 & 0.023 \\
\hline Yes & 45 & 19 & & \\
\hline No & 95 & 21 & & \\
\hline Comorbidity with cancer & & & 4.258 & 0.039 \\
\hline Yes & 20 & 9 & & \\
\hline No & 120 & 31 & & \\
\hline Mechanical ventilation & & & 2.209 & 0.331 \\
\hline No mechanical ventilation & 102 & 26 & & \\
\hline $\begin{array}{l}\text { Non-invasive mechanical } \\
\text { ventilation }\end{array}$ & 5 & 1 & & \\
\hline $\begin{array}{l}\text { Invasive mechanical } \\
\text { ventilation }\end{array}$ & 33 & 13 & & \\
\hline Smoking history & & & 1.029 & 0.310 \\
\hline Yes & 82 & 21 & & \\
\hline No & 58 & 19 & & \\
\hline First admission for AECOPD & & & 1.546 & 0.214 \\
\hline Yes & 96 & 24 & & \\
\hline No & 44 & 16 & & \\
\hline Duration of COPD & & & 0.111 & 0.739 \\
\hline$\leq 5$ years & 35 & 9 & & \\
\hline$>5$ years & 105 & 31 & & \\
\hline $\begin{array}{l}\text { Transfer to a rehabilitation } \\
\text { hospital after discharge }\end{array}$ & & & 0.016 & 0.900 \\
\hline Yes & 11 & 3 & & \\
\hline No & 129 & 37 & & \\
\hline Hypertension & & & 0.004 & 0.947 \\
\hline
\end{tabular}

Table 2 (continued)

after, in 2017 the European Respiratory Society/American Thoracic Society guideline for AECOPD strongly recommend that non-invasive mechanical ventilation used to treat patients with acute or acute-on-chronic respiratory failure (20).

Older age was also an important cause of death in other populations. Therefore, it was included in the multivariate analysis. Low BMI is associated with hospitalization and
Table 2 (continued)

\begin{tabular}{|c|c|c|c|c|}
\hline Variables & $\begin{array}{c}\text { Discharged } \\
\text { with stable } \\
\text { COPD }\end{array}$ & Death & $\chi^{2}$ value & $P$ value \\
\hline Yes & 51 & 14 & & \\
\hline No & 89 & 26 & & \\
\hline $\begin{array}{l}\text { Chronic pulmonary heart } \\
\text { disease }\end{array}$ & & & 0.211 & 0.646 \\
\hline Yes & 75 & 23 & & \\
\hline No & 65 & 17 & & \\
\hline Cardiovascular disease & & & 0.344 & 0.558 \\
\hline Yes & 99 & 27 & & \\
\hline No & 41 & 13 & & \\
\hline Diabetes & & & 0.000 & 0.984 \\
\hline Yes & 15 & 4 & & \\
\hline No & 125 & 36 & & \\
\hline Respiratory failure & & & 0.891 & 0.345 \\
\hline Yes & 96 & 25 & & \\
\hline No & 44 & 15 & & \\
\hline $\mathrm{pH}$ value & & & 0.860 & 0.354 \\
\hline $\mathrm{pH}<7.25$ & 27 & 10 & & \\
\hline $\mathrm{pH} \geq 7.25$ & 113 & 30 & & \\
\hline Hypoproteinaemia & & & 0.744 & 0.388 \\
\hline Yes & 60 & 19 & & \\
\hline No & 80 & 21 & & \\
\hline $\begin{array}{l}\text { Comorbidity with } \\
\text { bronchiectasis }\end{array}$ & & & 3.812 & 0.051 \\
\hline Yes & 25 & 3 & & \\
\hline No & 115 & 37 & & \\
\hline
\end{tabular}

AECOPD, acute exacerbation of chronic obstructive pulmonary disease; RICU, respiratory intensive care unit; COPD, chronic obstructive pulmonary disease.

readmission for AECOPD $(21,22)$. Weight loss can cause a high mortality rate in long-term follow-up (12-16). Low BMI had the same result in this study. Roberts et al. reported that low health literacy had been linked to inferior technique in administering medications in the COPD population (23). Beatty and his colleague (24) reported that inhalation devices were hard for low health literate patients to master. Although the patients had 
Table 3 Cox analysis results of AECOPD

\begin{tabular}{lccccc}
\hline Variable & $\beta$ & S.E. & Wald $\chi^{2}$ & $P$ & OR (95\% Cl) \\
\hline Education & & & 5.047 & 0.080 & $8.264(1.106-61.759)$ \\
$\quad$ No education & 2.112 & 1.026 & 4.235 & 0.040 & $5.365(0.657-43.825)$ \\
$\quad$ Primary school & 1.680 & 1.072 & 2.458 & 0.117 & $2.362(1.202-4.640)$ \\
Older age & 0.859 & 0.345 & 6.218 & 0.013 & $2.095(1.080-4.063)$ \\
Low BMI & 0.740 & 0.338 & 4.789 & 0.029 & $1.351(0.706-2.588)$ \\
Bedridden & 0.301 & 0.332 & 0.825 & 0.364 & $2.050(0.941-4.464)$ \\
Comorbidity with cancer & 0.718 & 0.397 & 3.267 & 0.071 & 0.072 \\
Comorbidity with bronchiectasis & 1.095 & 0.609 & 3.235 & & $2.988(0.906-9.851)$ \\
\hline
\end{tabular}

AECOPD, acute exacerbation of chronic obstructive pulmonary disease.

experiences with inhalers, none of the 23 patients showed $100 \%$ correct use at baseline. Even after re-education and re-demonstration, only 1 patient was able to correctly demonstrate $100 \%$ of the steps. This made us realize that most patients are lack of targeted health education after discharged. A systematic review of 85 studies showed that health literacy has a positive association with level of education (25). Health literacy scores were also positively related to education level in elderly people in China (26). A unique group of Chinese population included in this study, whose average age is $(71.91 \pm 9.14)$. Different from the popularizing high school education in developed Western countries elderly population, more than half of the patients had no education in this study. Most of them were born at the beginning of the founding of New China, and it was difficult for them to receive formal education. No education also means low health literacy. Compared with junior high school or higher, no education had a more than 8-fold increased risk of death. However, a systematic review reported that supported self-management could not change the mortality of COPD patients after discharged from hospital (27). In recent multicentre study in the UK, using a "care-bundles" approach which included inhaler technique assessing, smoking cessation, and pulmonary rehabilitation, etc., cannot change the mortality of AECOPD patients after discharge (28). COPD care bundles were not effectively implemented in that study. It may require a better health management plan when patients of AECOPD discharged.

In patients who were bedridden or had comorbidity with cancer, their disease was serious but that it was not an independent factor affecting their survival. These factors, which may be having collinearity with other factors or having less impact on the death of patients with AECOPD than other factors. A systematic review reported that AECOPD comorbidity with bronchiectasis patients had poorer mortality (29). In the follow-up of 6-month, 1- and 3 -year, Cox regression showed an increased risk of death for all-causes in AECOPD patients with bronchiectasis (30). However, that was not observed in this study, which may be related to the sample size.

Thanks to the development of communication technology this year, WeChat is installed on almost everyone's smart phone. Most patients or their families were willing to join the AECOPD follow-up group. Only 3 patients were lost to follow-up in this study.

\section{Limitation}

The 6-minute walking distance was not measured considering that this strength is not critical for AECOPD patients at discharge. The forced expiratory volume $1 \mathrm{~s}$ (FEV1) was not measured at admission for the same reason. Therefore, the GOLD Stage could not be determined. We think that it is necessary to carry out bedside lung function tests, which can be used for better patient diagnosis in future studies. Also, there was a huge gender discrepancy and there were hardly any females in this study making it difficult to apply the results to women. This was a retrospective study and there might be some information bias in data collection. A few family members of the patients can only describe the date of death to the nearest month. During the follow-up study, patients were only required to take medications and to perform pulmonary rehabilitation regularly relying on the conscious of the patient. 


\section{Conclusions}

In China, there are many older people who lack education. In this survey, more than half of the AECOPD patients had no education. It was very difficult to educate these patients. The results of this study suggested it may be very important for them to have additional specialized health education after discharge. Improvements are needed in future studies.

\section{Acknowledgments}

Funding: This work was supported by the Shanghai Pulmonary Hospital Foundation (No. fk201713) and Shanghai "Rising Stars of Medical Talent" Youth Development Program: Youth Medical Talents - Nursing Program (No. [2018]72). Shanghai Municipal Health Commission Foundation (No. 201840107).

\section{Footnote}

Conflicts of Interest: All authors have completed the ICMJE uniform disclosure form (available at http://dx.doi. org/10.21037/apm.2020.04.30). The authors have no conflicts of interest to declare.

Ethical Statement: The authors are accountable for all aspects of the work in ensuring that questions related to the accuracy or integrity of any part of the work are appropriately investigated and resolved. The study was conducted in accordance with the Declaration of Helsinki (as revised in 2013). This study was approved by the Human Ethics Committee of Shanghai Pulmonary Hospital (No. $\mathrm{k} 18-125)$, and all subjects or family members were willing to accept this survey. As the study was retrospective, a waiver of informed consent was obtained from the human ethics committee.

Open Access Statement: This is an Open Access article distributed in accordance with the Creative Commons Attribution-NonCommercial-NoDerivs 4.0 International License (CC BY-NC-ND 4.0), which permits the noncommercial replication and distribution of the article with the strict proviso that no changes or edits are made and the original work is properly cited (including links to both the formal publication through the relevant DOI and the license). See: https://creativecommons.org/licenses/by-ncnd/4.0/.

\section{References}

1. Lozano R, Naghavi M, Foreman K, et al. Global and regional mortality from 235 causes of death for 20 age groups in 1990 and 2010: a systematic analysis for the Global Burden of Disease Study 2010. Lancet 2012;380:2095-128.

2. Zhong N, Wang C, Yao W, et al. Prevalence of chronic obstructive pulmonary disease in China: a large, population-based survey. Am J Respir Crit Care Med 2007;176:753-60.

3. Hillas G, Perlikos F, Tzanakis N. Acute exacerbation of COPD: is it the "stroke of the lungs"? Int J Chron Obstruct Pulmon Dis 2016;11:1579-86.

4. Hartl S, Lopez-Campos JL, Pozo-Rodriguez F, et al. Risk of death and readmission of hospital-admitted COPD exacerbations: European COPD Audit. Eur Respir J 2016;47:113-21.

5. Jinjuvadia C, Jinjuvadia R, Mandapakala C, et al. Trends in Outcomes, Financial Burden, and Mortality for Acute Exacerbation of Chronic Obstructive Pulmonary Disease (COPD) in the United States from 2002 to 2010. COPD 2017;14:72-9.

6. Chen PK, Hsiao YH, Pan SW, et al. Independent factors associate with hospital mortality in patients with acute exacerbation of chronic obstructive pulmonary disease requiring intensive care unit admission: Focusing on the eosinophil-to-neutrophil ratio. PLoS One 2019;14:e218932.

7. Seneff MG, Wagner DP, Wagner RP, et al. Hospital and 1-year survival of patients admitted to intensive care units with acute exacerbation of chronic obstructive pulmonary disease. JAMA 1995;274:1852-7.

8. 2017 Global Initiative for Chronic Obstructive Lung Disease, Inc. Global Initiative for Chronic Obstructive Lung Disease. Pocket Guide to COPD Diagnosis, Management, and Prevention: A Guide For Health Care Professionals 2017 Edition. Available online: https:// goldcopd.org/wp-content/uploads/2016/12/wms-GOLD2017-Pocket-Guide.pdf

9. Celli BR, MacNee W; ATS/ERS Task Force. Standards for the diagnosis and treatment of patients with COPD: a summary of the ATS/ERS position paper. Eur Respir J 2004;23:932-46.

10. Expert group on acute exacerbation of chronic obstructive pulmonary disease. Chinese expert consensus on the diagnosis and treatment of acute exacerbation of chronic obstructive pulmonary disease (2014 revision). Int J Respir 
2014;34:1-10.

11. Suissa S, Dell'Aniello S, Ernst P. Long-term natural history of chronic obstructive pulmonary disease: severe exacerbations and mortality. Thorax 2012;67:957-63.

12. McGhan R, Radcliff T, Fish R, et al. Predictors of rehospitalization and death after a severe exacerbation of COPD. Chest 2007;132:1748-55.

13. Soler-Cataluña JJ, Martínez-García MA, Román Sánchez P, et al. Severe acute exacerbations and mortality in patients with chronic obstructive pulmonary disease. Thorax 2005;60:925-31.

14. Groenewegen KH, Schols AM, Wouters EF. Mortality and mortality-related factors after hospitalization for acute exacerbation of COPD. Chest 2003;124:459-67.

15. Gunen H, Hacievliyagil SS, Kosar F, et al. Factors affecting survival of hospitalised patients with COPD. Eur Respir J 2005;26:234-41.

16. Koul PA, Dar HA, Jan RA, et al. Two-year mortality in survivors of acute exacerbations of chronic obstructive pulmonary disease: A North Indian study. Lung India 2017;34:511-6.

17. Halpin DM, Miravitlles M, Metzdorf N, et al. Impact and prevention of severe exacerbations of COPD: a review of the evidence. Int J Chron Obstruct Pulmon Dis 2017;12:2891-908.

18. Jones PW, Mullerova H, Agusti A, et al. Cardiovascular Disease Does Not Predict Exacerbation Rate or Mortality in Chronic Obstructive Pulmonary Disease. Am J Respir Crit Care Med 2018;197:400-3.

19. Davidson AC, Banham S, Elliott M, et al. BTS/ICS guideline for the ventilatory management of acute hypercapnic respiratory failure in adults. Thorax 2016;71 Suppl 2:ii1-ii35.

20. Wedzicha JA Ers Co-Chair, Miravitlles M, Hurst JR, et al. Management of COPD exacerbations: a European Respiratory Society/American Thoracic Society guideline. Eur Respir J 2017;49:1600791.

21. Kessler R, Faller M, Fourgaut G, et al. Predictive factors

Cite this article as: Cheng J, Lu M, Sun H, Mao Y. A survival analysis of patients with an acute exacerbation of chronic obstructive pulmonary disease discharged from the respiratory intensive care unit. Ann Palliat Med 2020;9(4):1812-1820. doi: 10.21037/apm.2020.04.30 of hospitalization for acute exacerbation in a series of 64 patients with chronic obstructive pulmonary disease. Am J Respir Crit Care Med 1999;159:158-64.

22. Pouw EM, Ten Velde GP, Croonen BH, et al. Early nonelective readmission for chronic obstructive pulmonary disease is associated with weight loss. Clin Nutr 2000;19:95-9.

23. Roberts NJ, Ghiassi R, Partridge MR. Health literacy in COPD. Int J Chron Obstruct Pulmon Dis 2008;3:499-507.

24. Beatty CR, Flynn LA, Costello TJ. The Impact of Health Literacy Level on Inhaler Technique in Patients With Chronic Obstructive Pulmonary Disease. J Pharm Pract 2017;30:25-30.

25. Paasche-Orlow MK, Parker RM, Gazmararian JA, et al. The prevalence of limited health literacy. J Gen Intern Med 2005;20:175-84.

26. Liu YB, Liu L, Li YF, et al. Relationship between Health Literacy, Health-Related Behaviors and Health Status: A Survey of Elderly Chinese. Int J Environ Res Public Health 2015;12:9714-25.

27. Majothi S, Jolly K, Heneghan NR, et al. Supported selfmanagement for patients with COPD who have recently been discharged from hospital: a systematic review and meta-analysis. Int J Chron Obstruct Pulmon Dis 2015;10:853-67.

28. Morton K, MacNeill S, Sanderson E, et al. Evaluation of 'care bundles' for patients with chronic obstructive pulmonary disease (COPD): a multisite study in the UK. BMJ Open Respir Res 2019;6:e000425.

29. Du Q, Jin J, Liu X, et al. Bronchiectasis as a Comorbidity of Chronic Obstructive Pulmonary Disease: A Systematic Review and Meta-Analysis. PLoS One 2016;11:e0150532.

30. Crisafulli E, Guerrero M, Ielpo A, et al. Impact of bronchiectasis on outcomes of hospitalized patients with acute exacerbation of chronic obstructive pulmonary disease: A propensity matched analysis. Sci Rep 2018;8:9236. 